audit compared with expected population numbers - perhaps, at least in part, reflecting differing workload and staffing issues and level of support from clinical audit departments. There was considerable variation in the proportion of patients being seen within this timeframe, ranging from $55 \%$ in London to $28-39 \%$ elsewhere in the UK. The number of consultants per 100,000 of the population and the presence of an EIA clinic were the major identifiable factors associated with this. Anecdotally, the audit data is already being used to support arguments for additional support and the development of EIA clinics. A second iteration of the audit is planned for 2017-8 and it will be important to see whether, like other national clinical audits, it has driven measurable change in practice. All the indications so far are that it will and that it will also highlight the need to support and properly resource those units who are struggling to achieve the audit standards so as to give all patients with EIA the same high-quality care, wherever they live.

\section{Conflicts of interest}

SB has consulted in the field of Sjögren's syndrome clinical trials for a number of pharmaceutical companies, including Astra Zeneca/ Medimmune, Cellgene, Eli Lilly, Glenmark GSK, Novartis, Ono, Roche, Takeda and UCB.

\section{References}

1 British Society for Rheumatology. National clinical audit for rheumatoid and early inflammatory arthritis. London: BSR, 2016.
2. Scott DL, Wolfe F, Huizinga TW. Rheumatoid Arthritis. Lancet 2010;376:1094-108.

3 Sparks JA, Chang SC, Liao KP et al. Rheumatoid arthritis and mortality among women during 36 years of prospective followup: Results from the Nurses' Health Study. Arthritis Care Res 2016;68:753-62.

4 Listing J, Kekow J, Manger B et al. Mortality in rheumatoid arthritis: the impact of disease activity, treatment with glucocorticoids, TNF $\alpha$ inhibitors and rituximab. Ann Rheum Dis 2015;74:415-21.

5 National Audit Office. Services for people with rheumatoid arthritis. London: National Audit Office, 2009.

6 National Rheumatoid Arthritis Society. The economic burden of rheumatoid arthritis. Maidenhead: NRAS, 2010.

7 Harker R. NHS funding and expenditure. London: House of Commons Library, 2012.

8 Luengo-Fernandez R, Leal J, Gray A, Sullivan R. Economic burden of cancer across the European Union: a population-based cost analysis. Lancet Oncol 2013;14:1165-74.

9 National Institute for Health and Care Excellence. Rheumatoid arthritis in over 16s. NICE quality standard No 33. London: NICE, 2013.

10 National Institute for Health and Care Excellence. Rheumatoid arthritis in adults: management. NICE clinical guideline No 79. London: NICE, 2015.

\title{
The NIHR at 10: transforming clinical research 涉”
}

\author{
Authors: Sally C Davies, ${ }^{\mathrm{A}}$ Tom Walley, ${ }^{\mathrm{B}}$ Stephen Smye, ${ }^{\mathrm{C}}$ Lisa Cotterill ${ }^{\mathrm{D}}$ and Christopher JM Whitty ${ }^{\mathrm{E}}$
}

In the early 2000 s, clinical research in the UK was at a low ebb; most universities prioritised basic biomedical research, training opportunities were limited and clinician-researchers were declining in number and felt disenfranchised. An Academy of Medical Sciences report ${ }^{1}$ identified 'a substantial gulf between basic discoveries and converting such discoveries into innovations that directly benefit patients or prevent disease'. Government sponsored reports ${ }^{2}$ identified the possibility of using the NHS as a testbed for interventions

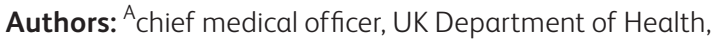
London, UK; ${ }^{B}$ director, NIHR Evaluations, Trials and Studies (NETS), Southampton, UK; ' NIHR Clinical Research Network specialty cluster lead, King's College London and R\&I director, Leeds Teaching Hospitals NHS Trust, Leeds, UK; ${ }^{D}$ director, NIHR Trainees Coordinating Centre, UK; ${ }^{E}$ chief scientific adviser, UK Department of Health, London, UK that would improve its efficiency and effectiveness while also promoting the UK life sciences industry. On paper, the Department of Health had a substantial budget for research and development but, in practice, most of this was historically tied into the bricks and mortar of major teaching hospitals, with little accountability for research outputs. The need for a relaunch of NHS-based clinical research was clear.

The result was a new government policy in $2006,{ }^{3}$ which set out the vision for a new National Institute for Health Research (NIHR), established in April that year, to 'create a health research system in which the NHS supports outstanding individuals, working in world-class facilities, conducting leading-edge research, focused on the needs of patients and the public' and a mandate to be radical in how it achieved that. This ambitious strategy was widely, but not universally, supported. The Cooksey review supported the NIHR and defined complementary roles for the two major public funders - the NIHR with clinical and applied research and the Medical Research Council biomedical and discovery science. 
The treasury gave an enhanced budget and money previously locked into NHS organisations was freed up over 3 years for reinvestment, in line with the national strategy.

Ten years on, ${ }^{4}$ the NIHR is the largest national clinical research funder in Europe. Major work areas include its own research programmes, NHS research, infrastructure support, research training and systems to underpin the clinical research environment more widely.

The NIHR now funds over $\mathfrak{E} 1$ billion of research each year, including around 750 randomised controlled trials at a time. The topics have all been identified as major priorities for the NHS, public health or social care and even with the multi-year lead time between research being initiated and policy change, many of these studies have already changed clinical practice and improved outcomes for patients. One example of many ${ }^{5}$ is the CRASH-2 study, ${ }^{6}$ which showed that an off-patent drug, tranexamic acid, can reduce mortality after trauma; initially adopted by the army, and later by UK ambulance services and accident and emergency departments, it is now used in routine practice. The NIHR also promotes best practice in the conduct of studies, supporting the research design service and clinical trials units, and ensures high rates of publication of results and access to data. ${ }^{7,8}$

Infrastructure includes biomedical research centres, which have proved to be powerhouses for translational research, cementing links between academic institutes and the NHS for mutual benefit. The Clinical Research Network provides infrastructure to support research funded by the NIHR and research funded by partners - including charities, industry and other government funders. This has significantly improved patient access to research; all NHS trusts in England now support opportunities for patients to participate in clinical research, with $42 \%$ of general practices research-active. Evidence is emerging ${ }^{9}$ of the wider beneficial impact on clinical services of research-active NHS organisations. Collaborations for Leadership in Applied Health Research and Care work at the interface between research and practice.

Developing the next generation of research leaders in clinical research is essential to the UK. The NIHR has helped to stem the decline in clinical research capacity, offering support at critical points in the career pathway for medical and other trainees; its importance was recently highlighted by the Royal College of Physicians. ${ }^{10}$ The NIHR has a programme of highly competitive training awards for medical and nonmedical professions. As part of the Integrated Academic Training Programme, pre-doctoral NIHR academic clinical fellowships (over 2,200 awarded since 2006) provide a vital introduction to research for clinicians during their specialty training. Additional trainees are supported via programme and infrastructure funding. The long-term financial commitment necessary to develop and maintain the next generation of research leaders in applied health research is there.

The NIHR has been built on solid foundations of excellence in both science and clinical practice across universities and the NHS, and given opportunities to clinicians to re-engage with research; it has attracted support from all of these constituencies; it has been promoted by successive governments, reaffirming their belief in the reciprocal link between better evidence, health and economic growth, as best exemplified by the life sciences sector.

There are two other groups without whose support, the NIHR could not succeed: industry, which has responded to the manifest improvements made by the NIHR in the NHS environment for research, bringing more trials and research to the UK and, most important of all, patients and the public. The NIHR has always stressed, as a core value, the importance of patient and public involvement and engagement at every step in the research process - from the setting of priorities through to the delivery, dissemination and implementation of results.

How will the NIHR fare in the future? The NIHR has thrived by collaboration with partners driven by the same aims; by promoting science of the highest quality; and by keeping its focus on the future needs of the NHS and the nation. There are clear challenges and opportunities ahead. Public health needs and responding to changing demographics will drive NIHR programmes. New areas of science, including the digital revolution and precision medicine technologies, have the potential to transform the nature of large areas of healthcare. The changing organisation of health services, public health and social care needs to be informed by solid evidence and subject to robust evaluation. The NIHR and clinical and applied research have travelled a long way in the past 10 years. The need for a world-class research system to ensure the NHS and public health and social care systems achieve the goal of clinical and care excellence is evident and, despite the well-recognised challenges, the progress of the NIHR over the past decade augurs well for the future of healthcare. And of course, as we consider a post-Brexit world, the NIHR will be at the core of the new industrial strategy.

\section{Conflicts of interest}

The authors have no conflicts of interest to declare.

\section{References}

1 Academy of Medical Sciences. Strengthening clinical research. London: Academy of Medical Sciences, 2003.

2 Department of Trade and Industry, Bioscience Innovation and Growth Team, Department of Health, BioIndustry Association. Bioscience 2015: improving national health, increasing national wealth. London: Department of Trade and Industry, 2004.

3 Department of Health. Best research for best health: a new national health research strategy. London: Department of Health, 2006.

4 Bell J. 10 years of the UK's National Institute for Health Research. Lancet 2016;387:1978-9.

5 Morgan Jones M, Kamenetzky A, Manville C et al. The National Institute for Health Research at 10 Years. An impact synthesis: 100 impact case studies. Cambridge: RAND Corporation, 2016.

6 CRASH-2 trial collaborators, Shakur H, Roberts I et al. Effects of tranexamic acid on death, vascular occlusive events, and blood transfusion in trauma patients with significant haemorrhage (CRASH-2): a randomised, placebo-controlled trial. Lancet 2010;376:23-32.

7 Macleod M, Michie S, Roberts I et al. Biomedical research: increasing value, reducing waste. Lancet 2014;383:101-4.

8 NIHR Journals Library. www.youtube.com/watch?v=8H03uxN_iTE [Accessed 20 September 2016].

9 Boaz A, Hanney S, Jones T, Soper B. Does the engagement of clinicians and organisations in research improve healthcare performance: a three-stage review. BMJ Open 2015;5:e009415.

10 Royal College of Physicians. Research for all. London: RCP, 2016.

Address for correspondence: Professor C Whitty, Department of Health, 79 Whitehall, London SW1A 2NS, UK.

Email: Chris.whitty@dh.gsi.gov.uk 